\section{THE USE OF RADIO-ACTIVE SUBSTANCES IN THERAPEUTICS.}

'THE British Medical Journal for February 4 contains a report of an address delivered before the Berlin Medical Society on January 18 by Prof. Wilhelm His, of the University of Berlin, on "The Treatment of Gout and Rheumatism by Radium." Prof. His was led to make the investigations upon which the address was founded by the consideration that radium, or at all events some of its derivatives, formed a constituent of certain natural curative springs, the action of which on gout and rheumatism is undoubted, though medical men have not been able to explain it satisfactorily. It soon became evident that both radium and radium emanation were capable of producing cures, which were especially remarkable in the case of gout and of the various rheumatic affections. The results obtained were reported by the lecturer about a year ago to the German Balneological Society. Since then his experience has considerably extended.

The patients dealt with include 100 cases of chronic rheumatism and 28 of uric acid gout. Of the former, 47 were improved, 29 considerably improved, 5 nearly cured, while 19 were uninfluenced by the treatment. The most interesting of the cases were those in which limbs renderer useless by the disease were almost completely restored by the treatment, which was continued for periods of three months or longer. In gout, the results were much more striking. Twenty-eight patients were kept under treatment and under observation for a considerable period. O these, 4 remained unaffected, while in 24 a marked improvement in the condition was achieved. Some of the patients have remained free from symptoms for a year after the termination of the treatment.

The most remarkable effect is noted in the behaviour of the uric acid in the blood. Under the influence of radium emanation, the blood loses its uric acid within a few weeks. This was observed in 15 cases out of 18 . On the other hand, the uric acid persisted in the blood of 3 patients even after a severe course of treatment. On two occasions actual deposits of uric acid under the skin of the ear (so-called "tophi ") were seen to disappear during the treatment. The clinical improvement did not always run parallel with the uric acid content of the blood. Thus very marked improvement was obtained in a patient by energetic treatment, though the blood continued to contain uric acid. In another patient no uric acid was present in the blood either at the beginning or the end of the treatment, although he had gouty nodules all over his body.

When water containing radium is drunk, part of the emanation is taken up in the inspired air, and another part is absorbed from the stomach and intestine. Emanation behaves like every other gas which is not a normal constituent of the body. It is excreted to a very slight extent through the kidneys, and to a large extent in the expired air. When the treatment is carried out by baths, absorption is only continued so long as the patient remains in the atmosphere laden with emanation from the bath water, and the foreign gas is excreted immediately. On the other hand, when carried out by means of drinking waters, the absorption takes place slowly from the intestine, and the body is being constantly supplied with fresh doses of emanation for three or four hours after a single dose. When the patient is given from three to five doses during the day, emanation can be detected in the expired air at any period of the day.

Radium itself behaves in the body like other heavy metals; that is to say, it is absorbed slowly, and the absorbed quantity is excreted again through the intestine. So long as it is present in the body, small quantities of emanation are continuously developed from it. It is therefore clear that the most active application of emanation is achieved when the individual is breathing an atmosphere which contains a certain quantity of radium emanation. Under these conditions, an equilibrium will rapidly be established between the emanation content of the outer air and that of the blood. This equilibrium will be maintained so long as the body remains in this atmosphere. The emanation content of the blood will reach a level in this way which can only be attained by the drinking of NO. 2 I6I, VOL. 86$]$ exceptionally large quantities of water containing radium. Experiments have shown that it is usually sutficient for the purpose of obtaining definite curative results, and of ridding the blood of gouty patients of uric acid, to place the patient in an air containing from two to four " making units" per litre for two hours a day. "Emanators have been constructed on this principle. A stream of oxygen bubbles through a fluid containing a salt of radium and is saturated with emanation. The emanation issuing from the fluid is distributed equally in the air of the room by a ventilator. 'This method, however, has the disadvantage that it can only be applied when a special emanator is available. A portable inhalation apparatus has also been constructed.

With regard to the mode of action of radium, the most important factor appears to be the property possessed by radium of rendering various ferments of the body more active than usual. This power of activising ferments has been dernonstrated in the case of pancreatin, pepsin, lactic acid ferment, diastatic ferments, and autolytic ferments. It is probable that the same is true of numerous other ferment actions in the body, though not for all; for example, it is known that the excretion of sugar by diabetics is not influenced by radium. In the case of gout, this property of radium can be demonstrated in a very clear manner. The disturbance in gout has been shown to depend on $\dot{a}$ slowing of the purin body metabolism, and not only is the formation and breaking down of uric acid slowed, but the mutual relations of the two processes are altered. In the gouty this is shown by the fact that, on a diet free from purin, though containins nucleic acid, the uric acid formed is not completely excreted within five days, as is the case in healthy persons. After prolonged treatment with emanation, how ever, the excretion takes place as promptly and completely as in a healthy individual. Gudzent was further able to show that uric acid and its salts are dissociated into carbon dioxide and ammonia under the influence of this action, and he demonstrated in a very ingenious manner that neither radium nor radium emanation produces this dissociation. It is due to radium $D$. Thus the actions that come into play in the treatment of gout by radium are very varied. In addition to the autolytic action, the action inhibiting inflammation, and that alleviating pain, there is a specific action on the uric acid and its salts, and on the processes regulating the quantity of uric acid in the bòdy.

Another radio-active substance-mesothorium-has been prepared in considerable quantities by Dr. Otto Hahn. As compared with radium, the want of durability of this preparation is amply compensated by the greater ease with which it can be obtained from raw material. It is more than probable that other radio-active substances will be discovered, and will bring the treatment of gout and allied complaints by radio-active substances within the reach of all. A great deal of experiment and observation is still required, more particularly to make sure that no evil results may appear side by side with the undoubted benefit which has already been obtained.

A. C. Jordan.

THE AERO AND MOTOR EXHIBITION.

THIS exhibition opened at Olympia on Friday, March 24, and will continue until Saturday, April I, A general survey of the flying machines shown indicates that the crank inventor is less conspicuous than has been the case at former exhibitions, and that the British makers have achieved notable progress during the past twelve months both as regards design and workmanship. Most of the machines have evidently been designed and constructed with a view to military requirements. Thus among foreign machines is the Breguet three-section military biplane, one of the favourites with the French War Department. This machine is built almost entirely of steel, thus cutting down the number of parts and the amount of wiring. The spars of the wings consist of large diameter steel tubes, to which the ribs are elastically attached, forming a supple surface which is claimed to give almost entire automatic stability. Another French War Department machine is the Nieuport two-seater monoplane, chiefly remarkable for its high speed -63 miles per hour. 